\title{
Methodological Thoughts from the Linguistic Field ${ }^{1}$
}

\author{
William D. Davies \\ Department of Linguistics, The University of Iowa, 553 English Philosophy Bldg; \\ Iowa City, Iowa, the USA \\ e-mail: william-davies@uiowa.ed
}

\begin{abstract}
Data are the heart and soul of any linguistic research. Regardless of how incisive an analysis might be, or how clever, it can never be any better than the data it is based upon. For the field linguist gathering data, important considerations include the selection of informants, the number of informants selection, and data collection techniques. Different research objectives, be they descriptive, prescriptive or theory-driven, require techniques appropriate to those particular goals and should be evaluated within the context of inquiry. What follows is a consideration of the techniques generally used by field linguists with a general descriptive goal within the framework of generative linguistics.
\end{abstract}

Key words: field linguistics, generative linguistics, direct elicitation, Bahasa Madura (Madurese)

To properly evaluate any kind of fieldwork, it is necessary to understand the context in which it is undertaken, to understand the goals that the field researcher seeks to accomplish, be they descriptive, prescriptive or theory-driven. A particular set of methods is required for reliable dialect studies, in which, for example, the same carefully crafted elicitation questionnaire must be administered to a large, representative sample. To construct a pedagogical grammar, one needs to find the acknowledged experts of a particular language and develop a far-reaching inventory of structures upon which the experts agree. An instrumental acoustic analysis requires yet different considerations, finding the appropriate phonetic environments that control for any unintended and unwanted phonological effects or interference.

\footnotetext{
${ }^{1}$ This is a revised and somewhat expanded version of a seminar entitled 'Some Pains and Pleasures in Linguistic Field Research' delivered at Petra Christian University on 23 July 2008.
} 
In the case of my research, the goal is the goal of generative linguistics: to model the way that language is organized in the brain, to discover the boundaries of the ways in which human languages can differ and how they must be alike. In short, the goal is to determine what a possible human language is. To understand the structure of human language in general, it is necessary to have accurate and comprehensive descriptions of individual languages. To do this we must test the limits of language and document the results.

Additionally, one of my goals for the past 10 plus years has been to bring Bahasa Madura, a regional language in Indonesia, into the global discussion. References to it have been somewhat limited in the Western linguistics literature. There has been discussion of the Madurese vowel harmony system (Stevens, 1968, 1980; Cohn, 1993 a, b; Trigo, 1987, 1991; Anderson, 1991) and the unusual type of reduplication it exhibits (Stevens, 1968, 1985 \&1994; Wilbur, 1973; Marantz, 1982; Steriade, 1988; Silverman, 2002). But beyond this, there is very little. Within the modern Western linguistics tradition of the past 50 years or more, the method of inquiry that I use is quite standard and my work is fairly self-explanatory to that audience. However, one problem I sometimes face in other environments is explaining myself and what I do. This takes place in a couple of different ways.

First, when I tell people outside of Indonesia that I study the grammar of Bahasa Madura, they typically ask where it is spoken and how many people speak it. They are usually surprised to hear that Madurese is the fourth most widely spoken language in Indonesia (following Bahasa Indonesia, Bahasa Jawa, and Bahasa Sunda) and that there are roughly 6.8 million speakers. That is, more people speak Bahasa Madura than speak some much better known and more thoroughly studied languages such as Danish, Finnish, Hebrew, Irish, Norwegian, and a host of others, and therefore the language should be of as much interest to linguists as these others have been.

Second, when I am in other parts of Indonesia, people often ask why I do research on Bahasa Madura, why not Bahasa Jawa, Bahasa Sunda, Bahasa Bali, or some other 'more desirable' language. The answer actually gets to the heart of the generative linguistics enterprise. The explanation is that to a generative linguist, with the goals of discovering the principles underlying the organization of human language, any language people use to communicate, to express themselves and their culture, to live their daily 
lives, to transact business is important to study. What we can discover about any particular language tells us something more about ourselves as people and, more to the central goals of generative linguistics, about ourselves as biological entities.

Once people accept this explanation for conducting research on Bahasa Madura, the next question is typically why my research is carried out primarily in Bangkalan, a city in the western district of Madura island, Indonesia. It is acknowledged that Sumenep, home of the royal court, is where the 'best' Bahasa Madura is spoken. And this is something generally understood and acknowledged by the Madurese people themselves. However, the response to this question is pretty much the same as the response to the question of why study Bahasa Madura at all. The interest of generative linguists is not prescriptive grammar but descriptive grammar. The language that people actually use is that which theoretical linguists need to account for. And the language that people actually use is sometimes at odds with the recognized prescribed norm. A couple of quick examples from English illustrate this.

\section{Descriptive and not Prescriptive}

First, for years English teachers have taught their students that they should not use split infinitives. That is, no words should intervene between the infinitival marker to and the verb that goes with it. According to this view, the following line from the introduction to the 1960's TV show Star Trek was considered ungrammatical or at least substandard English:

(1) "...to boldly go where no man has gone before."

Actually when people speak, they frequently and very naturally utter split infinitives. This is a controversy that has been going on for some time. George Bernard Shaw was a champion of the split infinitive, writing the following in a letter to the Times of London:

There is a busybody on your staff who devotes a lot of time to chasing split infinitives: I call for the immediate dismissal of this pedant. It is of no consequence whether he decides to go quickly or to quickly go or quickly to go. The important thing is that he should go at once. (Lebovits, 2008) 
The fact is that the use is so prevalent that in 1998 The Oxford American Desk Dictionary finally changed its stance and admitted that the rule against split infinitives is one not to be taken seriously.

Another clear example is the admonition against ending a sentence with a preposition. The problem with this dictum is that in natural speech it is very rare to hear someone front a preposition in a question. Thus, people naturally say (2a) and not (2b).

(2) a. Who did you go to the movies with?

b. With whom did you go to the movies?

The sentence in (2b) with the preposition fronted with the question word is quite unnatural in spoken English. Studies of English as a second language learners show that non-native speakers of English learn the structure with the preposition at the end of the sentence first (that is, (2a)), overwhelmingly so, even though the parallel structure is unacceptable in their own language (Bardovi-Harlig, 1987). Actually, English is quite unusual in allowing this construction, which is referred to as 'preposition stranding'. However, that it is possible and that it is very rare are thus important facts that natural speech can teach us. One of the jobs of generative linguistic theory is to attempt to explain why this is so. In addition, language is constantly changing, and it is important to keep up with those changes and try to explain them as well.

Therefore, generative linguists seek to describe the grammar of a language in terms of how people actually use it or can potentially use it. But this is the particular viewpoint of generative linguistics. This in no way implies that other viewpoints are incorrect. It is simply that as all methodologies and procedures of inquiry must be evaluated in terms of the goals of study, so too must the methodologies and procedures used in data collection in the field by a linguist with a generative orientation.

\section{METHODS}

\section{Collecting Data}

Within generative linguistics any source of data, if reliable, is considered legitimate. Written language, natural dialogue, intuitions of speakers are all important sources of data. In my work, I collected data from the following sources: 
1. existing accounts of the language (e.g. Kiliaan, 1897; Stevens, 1968; Moehnilabib, Wahab, Prijambada, Huda, and Ghazali, 1979),

2. recorded narratives and conversations (provided by my primary language informants),

3. narratives and stories published in Madurese (e.g. Campaka (Imron, 1979; Santre Gudhigan (Asmara, 1984)),

4. dictionaries (e.g. Safioedin, 1977), and

5. direct elicitation (i.e. asking informants for their judgment about structures).

Of the various methods, direct elicitation is particularly important. If the goal is to understand what the limitations are on a grammatical construction, or what they are not, it is necessary to have a sufficient number of tokens of a structure in enough environments to observe the phenomenon. It is frequently impossible to gather enough information, or enough of the necessary information, to get at the heart of the matter.

\section{Informants ${ }^{2}$ and working with them}

That said, we all know that things are never all that simple and there are many places where the research can go wrong. The trickiest part can be finding the right people to work with. I have had good luck with this, but have had some bad luck as well. When I was studying the Choctaw language many years ago when doing my dissertation, I began to work with some people who at first blush appeared to be knowledgeable informants but who turned out not to be fluent speakers of the language. I eventually discovered that too often they could not 'find' the Choctaw word for something. That can happen to all speakers sometimes. But in this case it was too frequent for me to have any confidence in the information I was getting. I eventually righted that problem and found reliable informants.

So, now in seeking informants to work with, I consult with people who might know of the right folks. Although it is not strictly necessary, I work

\footnotetext{
${ }^{2}$ Many field linguists in the United States refer to the native speakers that they work with as 'consultants', not 'informants'. This is due to the perception among some that 'informant' brings to mind 'informer' and the negative connotations associated with that word and outsiders. However, to avoid any confusion here, I adopt the terminology familiar in the Indonesian setting.
} 
predominantly with well-educated people who are recognized as wellspoken and knowledgeable in the use of the language and are consistent in their judgments. Of course, this cannot be taken at face value. Therefore, when working with a new informant I develop a baseline questionnaire with which I check on a broad survey of well-accepted facts or facts known to me from previous work. This includes: transitive and ditransitive verbs, active intransitive verbs, stative verbs (both intransitive and transitive), imperative and negative imperative sentences, hortative sentences, existential sentences, equational and locative sentences, causative sentences, interrogative sentences (including yes-no questions, constituent questions, and choice questions), clefted constructions, sentences with clausal complements of various types, and other. Please see the appendix for examples of each type of construction.

It is important to keep in mind that there has been much work on varieties of English that have sometimes been labeled 'substandard'. William Labov is well-known for his pioneering work on Black English Vernacular (now more generally referred to as African-American Vernacular English). Recently some work on the English spoken by many people in Belfast, North Ireland has drawn considerable attention. In Belfast English the following sentences (from Henry, 1995) are considered acceptable:

(3) Belfast English It wouldn't do for to say that. They seem for to have gone. Who did John hope would he see? What did Mary claim did they steal?

While certainly not Standard English, these structures are used by speakers of Belfast English, and data of this sort has influenced certain theoretical proposals regarding the structure of dependent nominal clauses and the formation of questions in complex sentences.

In addition to selecting good informants, it is necessary to see how comfortable people are with a particular method of data collection. People are sometimes better at some tasks than they are at others. One couple that I worked with for a while on Madura clearly fit the criteria of welleducated, well-spoken, and consistent in their acceptability judgments. However, they were actually quite insistent on only accepting a narrow 
range of sentence types in Bahasa Madura, and frequently would not consider grammatical some constructions that other speakers were perfectly comfortable with. Direct elicitation was not a good match for them. However, they did provide extremely valuable data by way of informal conversations with each other and through recorded narratives. Ironically, these sources of data included some of the constructions that they would not accept in the elicitation sessions.

I got off to a very bumpy start with another informant I worked with. At the beginning, this man, a teacher and former member of the Madurese parliament, got quite upset with me and the types of questions I was asking. He apparently felt that I was either testing him or asking stupid, very illinformed questions about Madurese. After the first two sessions, he was prepared to quit the project. However, my research assistant carefully explained to him what our methodology was and what the goal of our work was, and he agreed to stay on for a bit longer. Eventually, he actually started to enjoy the process and in so doing felt that he discovered some things about his own language that he was unaware of. He eventually became the most enthusiastic and supportive informant on the project. He was constantly suggesting alternative ways to say things that really helped move the research along. We still meet and do work together.

Another important factor in working with informants is to ensure that the informant gives consistent judgments. If not, the data are obviously going to be unreliable. To ensure such consistency it is important to recirculate questions and to ask about structures in a variety of environments. For example, I did this when investigating the passive form of what we can call 'semantically transitive stative verbs', that is, verbs that describe states but require two noun phrases, verbs such as baji' 'hate', enga' 'remember', esto 'love', kasta 'regret', lebur 'like', loppa 'forget', ngarte 'understand', parcaja 'believe', tao 'know', tresna 'love', yaken 'be sure', and others. I would ask about some of the verbs in one elicitation, sometimes asking about the same verb with a different kind of subject or object. Asking about sentences such as those in (4), which are not perfect in English but are fine in Bahasa Madura, the verb occurring as ekaloppae.

(4) Her teacher's name was forgotten by Ina.

The assignment was forgotten by the students.

To bring the cake to the party was forgotten by Bu Siti. 
I have found that this even is true with respect to sentences from spontaneous speech. At times, we all make mistakes, repair false starts, and so on. It is important to allow speakers to 'correct' themselves if they feel the need. Therefore, it is a good idea to include sentences from recorded dialogues or narratives in elicitation sessions as well.

It can also be instructive to check such sentences with other informants. In recent work, I have found that sentences first offered in a text by a particular informant and later rejected by that informant as unacceptable have been judged as perfectly acceptable by other informants. By way of example, the following sentence was taken from a narrative told by one of my informants.

(5) Mon manossa lo' bisa ng-okor arapa me' pas tombu adha' bungkel-la. if human not can AV-measure why EMPH then grow not.exist root-DEF 'Humans are unable to figure out why it grows without roots.'

When asked recently, the informant judged it unacceptable, yet four other informants judged it well-formed. Needless to say, it is important to check this sentence with the original informant another time or two.

This leads to the question of how many informants one should have. It is important to have a sufficient number to ensure a representative sample. While a single speaker can provide a notion of a particular idiolect of a language and a start in a general direction and general understanding of a language, individuals can not only be internally inconsistent (as we see with the example of a informant rejecting as unacceptable a sentence he gave in a narrated story) but they can potentially be unrepresentative. So how many informants represent the ideal number? This again depends on the nature of the research being undertaken. When doing quantitative research on a particular grammatical structure, it is naturally important to have a sufficient number of informants to ensure the validity of the statistics. For non-statistical descriptive work relying heavily on acceptability judgments, five or six solid, reliable informants will suffice. If this number of people provides general agreement on data, field linguists generally agree that the grammatical structure in question is robust.

Of course, the fact is that informants' judgments are not always identical. What do the field linguists do in that case? There can be a number of causes. First, the disagreement might point to some kind of 
dialectal or subdialectal difference, even if only a slight one. This difference might be attributed to background, age, socioeconomic group, and so on. Naturally, it requires further investigation to see what it can be attributed to. To take one example, there seems to be an age difference in the acceptability of the following Madurese sentence:

(6) Rudi percaja paman-na.

Rudi believe uncle-his

'Rudi believes his uncle.'

Speakers under the age of 50 tend to accept this sentence, while speakers over that age tend to consider it unacceptable. For the older speakers, the preposition $\mathrm{ka}$ 'to' is obligatory before pamanna. For the younger speakers it is optional.

In other cases, speaker difference may indicate that a particular speaker has an idiosyncrasy with respect to a particular construction. One informant had a very different use of the prefix ta- than did my other informants. The prefix ta frequently implies that the agent of the action did not perform the action voluntarily, and sometimes that the action was performed by mistake. For the majority of my informants the following sentence is acceptable and illustrative. The parentheses indicate that the preposition $b i^{\prime}$ is optional.

(7) Hasan ta-pokol (bi') Bambang.

Hasan TA-hit by Bambang

'Bambang accidentally hit Hasan.'

This particular informant, however, considered (7) unacceptable, offering (8) in its place.

(8) Bambang ta-pokol ka Hasan.

Bambang TA-hit to Hasan

'Bambang accidentally hit Hasan.

The other informants all rejected (8) as unacceptable. At this point, (8) is held in abeyance and will be checked with more informants.

For some linguists, it is these areas where people disagree that can prove the most interesting because the matters of disagreement must be 
accommodated by the theory. And they can therefore be theoretically interesting. This point is elaborated further on.

When working with informants, another factor to be considered is the length of the sessions. This, again, depends on the task. When doing direct elicitation, sessions should generally not last more than $1 \frac{1}{2}$ hours. The job of rendering acceptability judgments can be a taxing one, and results can be unreliable if informants get overly tired. Plan to take a break at some point. Determine the best time to do that by gauging the responses of your informant. It is advisable to plan to work on a number of different structures in a single session. To repeatedly work on the same structure can induce fatigue sooner and can compromise results. What is more, by having plenty of structures planned to work on, there is something to productive to move to in case (i) the results are not what you expect, (ii) the informant has particular difficulty finding precisely how to say particular sentences, and (iii) the informant seems bored with the construction. By having plenty to work on, it won't be necessary to cut the session short. Cutting a session short can have possible deleterious effects on a informant, such as (i) it can make him or her feel dissatisfied, (ii) it can make him or her resentful of the time spent, and (iii) it can make him or her feel as though the investigator has been let down. But sometimes it is necessary to cut a session short when nothing productive is taking place for whatever reason. Chatting or reviewing prior work is always an option.

One potential difficulty that is not really unique to studying Indonesian-type languages is the potential impact of interference or influence from Bahasa Indonesia especially, but also from Bahasa Jawa in the case of Bahasa Madura. This can be especially problematic from the standpoint of lexical items. But it can also occur with syntactic constructions at times, and so should be accounted for. For example, some younger speakers have offered sentences such as that in (9). (The ! annotation is used here to indicate that the sentence is unacceptable to the majority of speakers but acceptable to some perhaps due to the influence of Bahasa Indonesia.)

(9) !Buku rowa Ita baca. book that Ita read 'Ita read that book.'

The corresponding structure in Bahasa Indonesia is sometimes referred as the 'second passive' or 'passive 2', which is, of course, a perfectly acceptable in Bahasa Indonesia. It is not grammatical for most speakers of Madurese, 
nor has it ever been. However, if the influence of Bahasa Indonesia occurs frequently enough with a particular construction with a cohesive set of speakers (particularly younger speakers), it could well be the mark of a shift in the grammatical pattern of the language and should be taken seriously.

\section{Where informants disagree}

Perfectly knowledgeable and competent speakers can disagree on data at times without undermining the credibility of their judgment. In fact, it is frequently these differences in speakers' responses that can be particularly interesting and can teach us things about various structures and interpretations. Here I'd like to use a couple examples from Bahasa Madura.

The morpheme ta when prefixed to a verb stem frequently implies that the agent of the action did not perform the action voluntarily, and sometimes that the action was performed by mistake.

(10) a. Ali tapokol Hasan

'Hasan inadvertently hit Ali.'

b. Siti taentar dha' romana Ita. 'Siti inadvertently went to Ita's house.'

c. Sarpa'an tasabai bukuna Siti. 'Siti's book was accidentally put in the trash.'

Quite intentional actions or situations including an agentive adverb resist this structure. So, most speakers I've consulted consider the sentences in (11) to be unacceptable. (The * indicates that the sentence is ungrammatical.)
(11) a. *Ali tapokol Hasan ceppet
(Hasan quickly
b. *Juko' rowa tamassa' Siti te-ngate. inadvertently hit Ali.)
c. *Bambang tajalan neng embong.
(Siti carefully cooked that fish by mistake.) (Bambang inadvertently walked in the road.)

There are some interesting cases where the speakers I've consulted have had different judgments. Among them is the sentence in (12). (The \% annotation indicates that some speakers accept the sentence and others do not.) 
(12) \%Juko' rowa tamassa' Siti. 'Siti cooked that fish by mistake.'

The split tells us something about the intentionality that some people see in cooking as opposed to some other activities.

Another situation that arises has to do with what are commonly referred to as 'control' structures, such as the English sentence in (13).

(13) They wanted to win the election.

In control, the subject of the main verb 'controls' or provides the reference of the subject of the infinitival clause. The normal case in Madurese is for the subject of the verb 'try' jajal to control the agentive subject of the subordinate clause, as in:

(14) Polisi nyajal nangkep maleng rowa. 'The police tried to catch that thief.'

Here the agent of the main clause polisi determines the referent of the subject of the subordinate clause, and thus, here, the police are the ones who are trying to do the catching.

Uniformly, speakers reject as unacceptable the sentence

(15) *Maleng rowa nyajal etangkep polisi. (That thief tried to be caught by the police.)

Essentially, one should have control over the action that one is trying to do, and getting caught by the police is not something ones tries to do. However, most, but not all speakers find the following sentence acceptable

(16) \%Maleng gila rowa nyajal etangkep polisi. 'That crazy thief tried to be caught by the police.'

Providing a rich enough context is sufficient for most speakers to allow the interpretation of the embedded subject to be 'coerced' by the situation. A crazy thief might try to get caught. Indeed it's likely only a crazy thief would do that. Still, with that situation some speakers will reject the sentence as unacceptable. For them, we might hypothesize that the semantic restriction on the relationship of the matrix subject and the element that it provides reference cannot be overridden. 


\section{FINDINGS AND DISCUSSION}

The above considerations regarding selection of informants, initial findings with informants, and those situations in which informants give conflicting judgments about sentences all must be brought to bear on the process and product of elicitation work. These results form the framework within which further elicitation takes place and lead to additional techniques and their place in a well-balanced data collection approach.

\section{The importance of context}

The 'crazy thief' example above brings to light another important aspect of conducting elicitation research. Sufficient context can improve the acceptability of a sentence. To take another example from English, when asked about the acceptability of the following sentence, most native speakers of English balk, and reject it as proper English.

(17) The figs you were saving for the party, I saw Eric eating dozens of.

And I will admit that at first blush it sound pretty ragged. However, reconsider the sentence in light of the following scenario:

(18) My roommate Eric can be a real problem sometimes. I gave him a quart of figs yesterday, but he said he didn't want any. He really only wants what he isn't supposed to have. So you won't be surprised at this. The figs you were saving for the party, I saw him eating dozens of.

A less extreme but similar example arises when I am teaching introductory syntax. I will write the following rather classic example on the board:

(19) Beans, I like.

And students will scratch their heads and indicate that they consider the sentence to be unacceptable. Again, however, context makes it perfectly acceptable if not preferred.

(20) I really don't care much for broccoli. But beans, I like. 
Thus, the grammaticality or acceptability of a sentence can be dramatically increased when the right context is found —a fact that must be kept in mind when conducting elicitation research.

\section{'Forced choice' tasks}

Frequently, though, fieldworkers do not provide a context with a sentence when they are checking for acceptability. This can lead to faulty results. To counteract this, another method that is gaining some currency in the field is the use of what is referred to in experimental psychology and linguistics work as a 'forced choice' task. That is, subjects of an experiment are given a scenario and then forced to provide a judgment about a sentence in light of the context. To give simple example, consider the sentences:

(21) a. Jeremy saw the gardener cut the roses.

b. Jeremy saw that the gardener had cut the roses.

Both are grammatical sentences of English. The question is when people use each one. In a forced choice test, a subject might be given a scenario such as the scenario in (22).

(22) Scenario Jeremy had returned from a long day at the office. He decided to have a cup of tea out on the back porch. While relaxing, he noticed that the hedge was no longer overgrown, as it was when he went to work in the morning.

a. Jeremy saw the gardener cut the roses.

b. Jeremy saw that the gardener had cut the roses.

Subjects can be given different tasks. In one, they might be presented with a single sentence —in this case (21a) or (21b) — and asked if the sentence accurately describes the situation. In another variant, following the presentation of the context, subjects could be asked to assign acceptability ratings for each sentence on a 1-5 likert scale.

This type of elicitation instrument is particularly popular in second language acquisition studies and is useful in situations where the researcher requires input from a larger number of subjects. When researching a 
construction in which there seems to be divergence of opinion on the part of speakers. One case within Bahasa Madura is the environment in which the pronominal elements $a b a^{\prime} n a$ and $a b a^{\prime} n a$ dibi' can occur.

(23) Scenario

Ina bi' Atin la akanca on-taon. Atin mapeggel tetanggana, ban bari' tetangana nemmone ban ngoca' dha' Ina. Samarena, sengko' ajelling Ina ban Atin e lon-alon acaca ka bara' ka temor. Ina abalai Atin bab aba'na dibi'.

benar salah

Ina and Atin have been friends for years. Atin made her neighbors made, and yesterday they find Ina and talked to her. Later, I saw Ina and Atin at the alun-alun talking and talking.

Ina was talking to Atin about herself.

true false

The results are interesting but inconclusive at this point. Further refinement of the test instrument may be required, including the possibility of changing the task for the subjects.

\section{Find only what's 'really there'}

A concluding point of consideration is an important and very real potential problem in data collection but one. One must take care in doing fieldwork not to discover what one hopes to find but to discover what is actually there to be found. Expectations based on knowledge of other languages or based on what has been taught or based on one's theoretical perspective can occasionally lead to incorrect analyses or tainted data. A single example should suffice.

A structure of particular interest to generative linguists is what is referred to as Raising. It is exemplified by the sentences in (24).

(24) a. It seems that Jake is very intelligent.

b. Jake seems to be very intelligent.

The (b) sentence is referred to as a 'raising' structure because the subject of the dependent clause in (a) has 'raised' to be the subject of the main clause. 
As detailed in Davies and Dubinsky 2004, raising has played a pivotal role in the development of generative linguistic theory, and every theory must have an account for such structures. Fieldworkers working in a generative framework will therefore attempt to elicit the structure in whatever language they study to see if the language has that structure. Of particular interest are raising structures such as (25b) and (25c).

(25) a. Sale believes that Dayat bought a new car.

b. Sale believe Dayat to have bought a new car.

c. Dayat is believed by Sale to have bought a new car.

The sentences in (25b) and (25c) are referred to as Raising to Object, as the standard analysis is that Dayat occurs initially in the subject position of the embedded clause but raises to be the object in (25b) and optionally made the subject of the passive in (25c). It has been claimed that language such as Indonesian, Bahasa Jawa, Bahasa Bali, and others have such a structure. And if you ask informants the right questions in the right way, you can elicit a structure that looks very much like this. The counterparts in Madurese are given in (26).

(26) a. Sale ngera ja' Dayat melle motor anyar.

b. Sale ngera Dayat melle motor anyar.

c. Dayat ekera Sale melle motor anyar.

However, digging a little deeper reveals that the structure in Madurese is actually more like the English structure in (27).

(27) Sale believes of Dayat that he bought a new car.

The structure in (27) is not Raising but what is referred to as Prolepsis. For reasons laid out in Davies 2005, I believe that the data show that this is the structure found in Madurese, and not Raising. If I am correct, the literature is replete with what quite likely are at least misanalyses and at worst misrepresentations of the facts. I came to the discovery in a round about way, after misanalyzing the equivalent structure in Javanese. However, following the data and not exclusively the theory lead to this realization. Regrettably, this situation can be replicated many times over. 


\section{CONCLUSION}

Naturally, there is much more that could and should be said about conducting research in the field. Only a single kind of research goal has been considered here, and the most important factor that must be kept in mind is that any research methodology must be evaluated in terms of the goals of the research, the questions that the researcher hopes to answer. As long as the methodology is consistent with the goals, then the research cannot be called into question on methodological grounds. Of course, that is not to say that the research cannot be rejected because the goals are questionable. But that is a different discussion entirely.

\section{REFERENCES}

Asmara, M. S. (1984). Santre Gudhigan. Jakarta: Departemen Pendidikan dan Kebudayaan

Bardovi-Harlig, K. (1987). Markedness and salience in second-language learning. Language Learning, 37, 385-407.

Cohn, A. C. (1993a). Consonant-vowel interactions in Madurese: The feature lowered larynx. Papers from the $29^{\text {th }}$ Regional Meeting of the Chicago Linguistic Society, 105-119.

Cohn, A. C. (1993b). Voicing and Vowel Height in Madurese, a Preliminary Report. In J. A. Edmondson, \& K. J. Gregerson (Eds.), Tonality in Austronesian languages. Oceanic Linguistics Publication no. 24.

Davies, W. D. (2005). Madurese prolepsis and its implications for a typology of raising. Language, 81, 645-665.

Davies, W. D., \& Dubinsky, S. (2004). The grammar of raising and control. Oxford: Blakwell Publishers.

Kiliaan, H. N. (1897). Madoereesche spraakkunst. Batavia: Landsderukkerij.

Lebovits, G. (2008). Do's, don'ts, and maybes: usage controversies. New York State Bar Journal, 80, 64.

Marantz, A. (1982). Re reduplication. Linguistic Inquiry, 13, $483-545$.

Moehnilabib, M., Wahab, A., Prijambada, S., Huda, N., \& Ghazali, A. S. (1979). Morfologi dan sintaksis Bahasa Madura. [Madurese morphology and syntax]. Jakarta: Pusat Pembinaan dan Pengembangan Bahasa, Departemen Pendidkan dan Kebudayaan. 
Safioedin, A. (1977). Kamus Bahasa Madura-Indonesia. [Madurese-Indonesian dictionary]. Jakarta: Pusat Pembinaan dan Pengembangan Bahasa, Departemen Pendidkan dan Kebudayaan

Silverman, D. (2002). Dynamic versus static phonotactic conditions in prosodic morphology. Linguistics, 40, 29-59.

Stevens, A. M. (1968). Madurese phonology and morphology. New Haven: American Oriental Society.

Stevens, A. M. (1980). Formative boundaries in phonological rules. In M. Aronoff, \& M.-L. Kean (Eds.), Juncture: Studia Linguistica et Philologica (p. 7). Saratoga, CA: Anma Libri.

Stevens, A. M. (1985). Reduplication in Madurese. Proceedings of ESCOL 1985, 232-243. Columbus, OH: The Ohio State University.

Stevens, A. M. (1994). Madurese reduplication revisited. In K. L. Adams, \& T. J. Hudak (Eds.), Papers from the Second Annual Meeting of the Southeast Asian Linguistics Society 1992 (pp. 357-381). Tempe, AZ: Arizona State University.

Steriade, D. (1988). Reduplication and syllable transfer in Sanskrit and elsewhere. Phonology, 5, 73-155.

Wilbur, R. (1973). The identity constraint: An explanation of the irregular behavior of some exceptional reduplicated forms. Studies in the Linguistic Sciences, 3, 143-154.

\section{APPENDIX}

\section{An Initial Elicitation}

I stated in the section on informants that an initial elicitation with a new speaker is important in determining the likelihood of that person being a reliable, knowledgeable informant. The type of baseline elicitation instrument that I used in my own work included structures in the categories described below. This is by no means an exhaustive list, nor is it meant to be. The goal is to get a sampling of a cross-section of structures of Madurese that help me determine whether or not the candidate is in general agreement with well-established facts of the grammar of the language. The interview proceeds by asking the informant how to say 'Mother walked to 
market' in Madurese and 'The children swam in the river' and so on. The informant is also invited to provide alternatives to his or her answers by my inquiring whether there are other ways to say the same thing or whether it would be possible to begin the sentence with, say, 'to market' rather than 'mother' (if the informant has indeed started the sentence with 'mother'). These types of questions become more important when dealing with transitive and intransitive verbs, where there are more participants as well as the possibility of active and passive counterparts. As the sentences below are merely illustrative examples of the structures to be investigated, their number is significantly lower than the number of sentences to be covered in the elicitation session.

1. active intransitive verbs

Mother walked to market.

The children swam in the river.

2. non-active intransitive verbs

The child fell from the chair.

The letter arrived yesterday.

3. stative intransitive verbs

The students are smart.

The wall is blue.

4. stative transitive verbs

The students understand the problem.

Father loves mother.

5. transitive verbs

Ali hit his little brother.

Big brother bought a new motorcyle.

6. ditransitive verbs

Ina sent a letter to Auntie.

Mother gave money to the child.

7. imperative and negative imperative sentences

Read your book!

Put the box there!

Don't read that book!

Don't put the box there!

8. hortative sentences

Let's read a book!

Let's kick the ball! 
9. existential sentences

There's a goat in the yard.

There's a package on the table.

10. equational sentences

Siti is a singer.

Pak Hasan is a teacher.

Ina's teacher is Pak Hasan.

11. locative sentences

The car is behind the house.

Mother is at the office.

12. causative sentences (with intransitive, transitive, and ditransitive base verbs)

Bambang made his father angry.

The cook sharpened the knife.

Mother made the boy walk home.

The boss made Ali work.

Father made Ina read the book.

Father made Bambang wash the car.

Mother made the children put their toys in a box.

Big sister made Ali give the book to her friend.

13. including yes-no questions

Is Siti a singer?

Did the teacher read the book?

Did Ali give the book to his friend?

14. choice questions

Does Ita like coffee or tea?

Are you reading a book or a magazine?

Is Ali working or sleeping?

15. constituent questions

Who bought a new car?

What bit your hand?

What is Mother reading?

What did Siti buy in Surabaya?

What did Auntie leave on the table?

Where did Auntie leave the package?

What did Mother give to the child?

Who did Mother give some money to?

Why did Bu Ina leave? 
How did they get to Malang?

How did Uncle catch so many fish?

When did they move to Jakarta?

16. clefted constructions

Little brother is the one that broke the window.

Bambang is the one that the goat bit.

Auntie is the one that mother gave the money to.

17. sentences with clausal complements of various types

Pak Dayat tried to fix the computer.

Ina thinks that Hasan bought a new car.

The students didn't know who to ask for help.

The workers began to paint the house.

Mother convinced Father to sell the car.

Pak Satim promised his wife that he would fix the door. 